\title{
NUMBER SENSE SISWA PADA MATERI EKSPONEN DITINJAU DARI GAYA KOGNITIF REFLEKTIF-IMPULSIF
}

\author{
Firdausin Nuzula
}

Program Studi Pendidikan Matematika, Fakultas Matematika dan Ilmu Pengetahuan Alam, Universitas Negeri Surabaya Email: firdausin.17030174006@mhs.unesa.ac.id

\section{Endah Budi Rahaju}

Program Studi Pendidikan Matematika, Fakultas Matematika dan Ilmu Pengetahuan Alam, Universitas Negeri Surabaya Email: endahrahaju@unesa.ac.id

\begin{abstract}
Abstrak
Number sense berperan penting dalam kehidupan sehari-hari yang dapat diperoleh dari pengalaman belajar sejak usia dini. Number sense merupakan kemampuan seseorang dalam memahami bilangan dan operasinya serta menggunakannya untuk menyelesaikan masalah secara fleksibel. Setiap individu memiliki number sense yang berbeda, salah satu penyebabnya adalah gaya kognitif. Penelitian ini bertujuan untuk mendeskripsikan number sense siswa pada materi eksponen yang ditinjau berdasarkan gaya kognitif reflektif dan impulsif. Subjek dalam penelitian ini adalah satu siswa bergaya kognitif reflektif dan satu siswa bergaya kognitif impulsif kelas X dengan peminatan Ilmu Pengetahuan Alam berjenis kelamin sama dan berkemampuan matematika setara. Instrumen penelitian yang digunakan meliputi Tes Gaya Kognitif (TGK), Tes Kemampuan Matematika (TKM), Tes Number Sense (TNS), dan pedoman wawancara. Berdasarkan hasil penelitian, subjek reflektif dan impulsif mampu menjelaskan definisi eksponen akan tetapi subjek impulsif tidak mengetahui hubungan bentuk akar dengan eksponen. Kedua subjek mampu mengubah bentuk eksponen dengan nilai ekuivalen. Subjek reflektif mampu menggunakan sifat perkalian, pembagian, dan perpangkatan eksponen. Sedangkan subjek impulsif dapat menggunakan sifat perkalian dan perpangkatan eksponen meskipun membuat beberapa kesalahan. Subjek reflektif dan impulsif menggunakan metode perhitungan mental dan kertas. Subjek reflektif mampu memberi alternatif lain penyelesaian TNS, namun tidak dengan subjek impulsif. Subjek reflektif mengecek kembali jawabannya, sedangkan subjek impulsif tidak mengecek kembali padahal subjek impulsif telah melakukan beberapa ketidaktelitian.
\end{abstract}

Kata Kunci: number sense, reflektif, impulsif, eksponen.

\begin{abstract}
Number sense has an important role in daily live, it can be obtained from learning experience from an early age. Number sense is ability to understand numbers and its operations, then it also use to solve the problem flexibly. Every student has different number sense which one of the causes is cognitive style. This research aims to descript students' number sense on exponential based on reflective-impulsive cognitive style. Subject in this research is one reflective student and one impulsive student grade $\mathrm{X}$ with specialization in natural science, in the same gender, and have equivalent math skills.. The research instruments consist of Cognitive Style Test, Math Ability Test, Number Sense Test, and interview guidelines. Based on the research result, reflective and impulsive subject can grasps definition of exponent but impulsive subject is not able to understand relation between swuare root and exponent. Both of them are able to change the form of exponent with equivalent value. Reflective subject is able to use multiplication, division, and powers. On other hands, impulsive subject is able to use multiplication and powers but made some mistakes. Reflective and impulsive subject use mental calculation and paper to solve Number Sense Test. Reflective subject able to give alternative solution to solve Number Sense Test, but not for impulsive subject. Reflective subject revise the answer and impulsive subject doesn't revise the answer so impulsive subject makes some mistakes because it is not careful to solve Number Sense Test.
\end{abstract}

Keywords: number sense, reflective, impulsive, exponent . 


\section{PENDAHULUAN}

Number sense menjadi topik matematika yang banyak diteliti dalam lingkup internasional dengan bermacammacam definisi yang diberikan pada number sense (Yang \& Wu, 2010; Mohammed \& Johnny, 2010; Clarke \& Wessels, 2014; Arslan, 2016; Hassan, 2016; Maghfirah \& mahmud, 2018; Zainal, 2018). Hal tersebut terjadi karena number sense memiliki peran penting dalam pembelajaran matematika. Selain itu, number sense juga dapat diterapkan dalam kehidupan sehari-hari dan membantu siswa mengembangkan pemikiran matematika yang fleksibel, kreatif, dan efektif (Yang \& Wu, 2010).

Number sense mengacu pada pemahaman atau kepekaan seseorang terhadap bilangan dan operasinya untuk menyelesaikan suatu masalah yang berkaitan dengan bilangan dan operasinya secara fleksibel (Zainal, 2018). Kemudian Maghfirah dan Mahmud (2018) mengatakan bahwa number sense mengacu pada intuisi yang baik dan pemahaman umum tentang angka, operasi, serta hubungan di antara mereka. Berdasarkan penelitian yang dilakukan oleh Tosto dkk. (2017), number sense memiliki hubungan dengan matematika yang bergantung pada aspek spesifik mana yang dipertimbangkan dan pada usia berapa. Dalam mempelajari matematika diperlukan kemampuan number sense sebab matematika mengandung unsur bilangan dan operasinya. Oleh karena itu number sense merupakan kepekaan seseorang dalam memahami bilangan dan operasinya serta menyelesaikan masalah dalam kehidupan sehari-hari yang berkaitan dengan bilangan secara fleksibel.

Number sense diperoleh individu dari pengalaman belajar sejak usia dini, dengan kata lain bahwa number sense merupakan hasil belajar matematika (Arslan, 2016; Maghfirah \& Mahmud, 2018). Namun, tidak semua siswa yang mempelajari matematika memiliki number sense yang baik. Meskipun siswa memiliki tingkat kompetensi yang tinggi dalam melakukan algoritma di dalam kelas, para siswa ini umumnya lemah dalam memahami makna bilangan dan operasinya, relatif ukuran bilangan, menyusun bilangan, dan mengenali efek operasi pada bilangan (Mohamed \& Johnny, 2010; Castronovo \& Gobel, 2012).

Siswa dengan number sense yang baik memiliki beberapa karakteristik seperti yang diungkapkan oleh NCTM dalam Maghfirah dan Mahmud (2018) yaitu memiliki pemahaman makna bilangan yang baik, dapat mengembangkan banyak hubungan antar bilangan, mengenali besaran relatif bilangan, mengetahui pengaruh relatif pengoperasian bilangan, dan mengembangkan referensi untuk mengukur objek serta situasi umum di lingkungan mereka. Dalam penelitian ini, indikator number sense diadaptasi dari Cheung dan Yang (2018) yang meliputi memahami makna bilangan dan operasinya, menggunakan beberapa representasi bilangan dan operasinya, memahami efek dari operasi bilangan, dan mampu menilai kewajaran komputasi dari strategi berbeda.

Setiap siswa memiliki tingkat number sense yang berbeda. Perbedaan tersebut disebabkan oleh hasil belajar matematika dan gaya kognitif (Chrysostomou, 2011; Arslan, 2016; Zainal, 2018). Rahmatina, Sumarmo, dan Johar (2014) mendeskripsikan gaya kognitif sebagai karakteristik seseorang dalam menerima, menganalisis, dan merespon suatu tindakan kognitif yang diberikan kepadanya. Kemudian, Olagbaju (2020) menyatakan bahwa gaya kognitif merupakan cara seseorang dalam memahami, memproses informasi, dan tindakan kognitif yang diterimanya secara berbeda-beda. Gaya kognitif memiliki pengaruh dalam kegiatan pembelajaran siswa, sebab cara siswa dalam memproses informasi mempengaruhi waktu yang digunakannya untuk memahami suatu informasi atau materi matematika. Dimensi gaya kognitif tersebut disebut gaya kognitif reflektif dan impulsif.

Gaya kognitif reflektif dan impulsif menunjukkan kecepatan seseorang dalam berpikir. Secara umum, siswa dengan gaya kognitif reflektif dicirikan dengan karakternya yang memikirkan suatu hal dari berbagai perspektif, cermat, dan membutuhkan waktu cukup lama untuk berpikir. Sedangkan siswa dengan gaya kognitif impulsif dicirikan dengan karakternya yang mudah terbawa oleh ide-ide baru dan menarik sehingga cenderung bertindak cepat dan tidak berhati-hati (Hassan, 2016). Dimensi gaya kognitif ini diukur menggunakan Matching Familiar Figure Test (MFFT) yang diadopsi dari Warli (2010). Tes tersebut dilakukan dengan mencocokkan gambar baku dengan gambar-gambar variasi. Variabel yang diukur dalam tes ini meliputi rata-rata waktu yang digunakan untuk menjawab hingga menemukan jawaban yang benar ( $t$ ) dan rata-rata frekuensi kesalahan siswa dalam menjawab $(f)$.

Sumaryanta, Priatna, dan Sugiman (2019) mengemukakan bahwa nilai Ujian Nasional Matematika di Indonesia pada tahun ajaran 2015-2018 adalah rendah untuk jenjang Menengah Pertama, Menengah Atas, dan Menengah Kejuruan. Rendahnya nilai Ujian Nasional tersebut disebabkan oleh beberapa faktor yang salah satunya adalah number sense siswa. Selanjutnya, Arslan (2016) menyebutkan bahwa materi eksponen dapat digunakan untuk mengukur number sense siswa. Iymen dan Paksu (2015) serta Ulusoy (2019) menyebutkan bahwa number sense siswa Sekolah Menengah dalam menyelesaikan soal eksponen di Turki adalah rendah. Kemudian Zainal (2018) melalui penelitiannya mengenai number sense siswa bergaya kognitif reflektif dan impulsif pada materi pecahan menghasilkan kesimpulan bahwa 
siswa dengan gaya kognitif reflektif dan impulsif jenjang Menengah Pertama memiliki number sense yang berbeda pada materi pecahan. Sehingga diduga number sense siswa pada materi eksponen juga berbeda apabila ditinjau dari gaya kognitif reflektif dan impulsif. Di Indonesia juga belum ada penelitian number sense yang fokus pada materi eksponen. Oleh karena itu, penelitian ini fokus menjelaskan kemampuan number sense siswa dengan gaya kognitif reflektif dan impulsif pada materi eksponen.

\section{METODE}

Penelitian ini tergolong penelitian kualitatif yang bersifat deskriptif untuk mendeskripsikan number sense siswa pada materi eksponen yang ditinjau dari gaya kognitif reflektif dan impulsif. Penelitian dilakukan pada 17 siswa dengan jenis kelamin sama di salah satu kelas X Mipa di SMA Negeri 2 Sidoarjo. Data penelitian diperoleh dengan menggunakan metode tes dan wawancara. Instrumen dalam penelitian ini meliputi Tes Gaya Kognitif (TGK), Tes Kemampuan Matematika (TKM), Tes Number Sense (TNS), dan pedoman wawancara. Seluruh instrumen penelitian telah divalidasi oleh Dosen Pembimbing dan guru mitra sehingga layak untuk digunakan.

TGK menggunakan Matching Familiar Figure Test (MFFT) yang diadopsi dari Warli (2010) yang sudah valid, reliabel, dan layak digunakan. TGK diberikan melalui Google Meet. Teknik analisis data tes MFFT dengan cara menghitung rata-rata waktu pertama kali subjek menjawab $(t)$ dan rata-rata frekuensi jawaban yang dipilih $(f)$ (Zainal, 2018). Berdasarkan data hasil analisis TGK didapatkan nilai median untuk rata-rata waktu $(t)$ yang digunakan siswa untuk mengerjakan setiap soal TGK sebesar 58,38 detik dan median untuk rata-rata frekuensi $(f)$ menjawab sebesar 2,15. Jadi, siswa dikatakan bergaya kognitif reflektif jika memiliki $t>59,38$ detik dan $f \leq 2,15$, sedangkan siswa dikatakan bergaya kognitif impulsif jika memiliki $t \leq 59,38$ detik dan $f>2,15$. Dari hasil TGK didapatkan sebanyak $35,3 \%$ siswa bergaya kognitif reflektif, 35,3\% siswa bergaya kognitif impulsif, dan $29,4 \%$ siswa bergaya kognitif lainnya. Hal ini sesuai dengan Zainal (2018) bahwa siswa dengan gaya kognitif reflektif dan impulsif berjumlah lebih banyak dibanding siswa dengan gaya kognitif lainnya.

TKM yang digunakan berbentuk essay yang diadopsi dari soal-soal Ujian Nasional Matematika SMP tahun 2018-2019 yang diberikan melalui Google Form. Teknik analisis data untuk TKM berdasarkan pedoman penilaian yang telah disusun peneliti. Berdasarkan hasil analisis TGK dan TKM didapatkan subjek penelitian. Kriteria subjek penelitian antara lain yaitu, 1) satu subjek bergaya kognitif reflektif dan satu subjek bergaya kognitif impulsif, 2) memiliki kemampuan matematika yang setara, 3) berjenis kelamin sama, 4) dapat berkomunikasi dengan baik. Subjek penelitian diberi TNS dan dilaksanakan wawancara untuk mendapatkan informasi lebih lanjut mengenai number sense siswa. Analisis data TNS berdasarkan indikator number sense pada materi eksponen dan analisis data wawancara menggunakan acuan analisis data kualitatif dengan model Miles dan Huberman yaitu reduksi data, penyajian data, dan penarikan kesimpulan. Dalam pengujian kredibilitas data, peneliti menggunakan triangulasi teori dan triangulasi waktu yaitu penelitian dilakukan dengan mempertimbangkan waktu pengumpulan data (Sugiyono, 2017). Adapun indikator number sense pada materi eksponen yang diadaptasi dari Cheung dan Yang (2018) disajikan pada tabel berikut.

Tabel 1. Indikator number sense

\begin{tabular}{|l|l|c|}
\hline \multicolumn{1}{|c|}{$\begin{array}{c}\text { Indikator } \\
\text { number sense }\end{array}$} & $\begin{array}{c}\text { Indikator number sense pada materi } \\
\text { eksponen }\end{array}$ & Kode \\
\hline $\begin{array}{l}\text { Memahami } \\
\text { makna } \\
\text { bilangan dan } \\
\text { operasinya }\end{array}$ & $\begin{array}{l}\text { Siswa dapat menggunakan konsep } \\
\text { bilangan berpangkat yaitu perkalian } \\
\text { berulang atau konsep bentuk akar }\end{array}$ & $\mathrm{C} 1$ \\
\hline $\begin{array}{l}\text { Menggunakan } \\
\text { beberapa } \\
\text { representasi } \\
\text { bilangan dan } \\
\text { operasinya }\end{array}$ & $\begin{array}{l}\text { Siswa dapat mengubah suatu ekspresi } \\
\text { eksponen menjadi ekspresi lain yang } \\
\text { ekuivalen dan sebaliknya sesuai } \\
\text { dengan sifat- sifat eksponen }\end{array}$ & $\mathrm{C} 2$ \\
\hline $\begin{array}{l}\text { Memahami } \\
\text { efek dari } \\
\text { operasi } \\
\text { bilangan }\end{array}$ & $\begin{array}{l}\text { Siswa dapat memanfaatkan sifat-sifat } \\
\text { operasi eksponen untuk menentukan } \\
\text { hasil operasi eksponen }\end{array}$ & $\mathrm{C} 3$ \\
\hline $\begin{array}{l}\text { Mampu } \\
\text { menilai } \\
\text { kewajaran } \\
\text { komputasi dari } \\
\text { strategi } \\
\text { berbeda }\end{array}$ & $\begin{array}{l}\text { Siswa dapat menggunakan strategi } \\
\text { (perhitungan mental, perhitungan di } \\
\text { atas kertas) yang efektif }\end{array}$ & $\mathrm{C} 4$ \\
\cline { 2 - 4 } & $\begin{array}{l}\text { Siswa dapat menggunakan strategi } \\
\text { yang berbeda dalam penyelesaian } \\
\text { soal }\end{array}$ & C5 \\
\cline { 2 - 4 } & $\begin{array}{l}\text { Siswa dapat menilai kewajaran hasil } \\
\text { komputasi dengan mengecek kembali } \\
\text { jawaban yang didapatkan }\end{array}$ & $\mathrm{C} 6$ \\
\hline
\end{tabular}

Berikut merupakan soal Tes Number Sense (TNS) yang diberikan pada subjek penelitian.

Tentukan nilai dari $\frac{\sqrt[\frac{2}{3}]{x^{\frac{1}{3}} y^{\frac{4}{3}}}}{x^{\frac{5}{6}} y^{-\frac{1}{4}}}:\left(\frac{1}{x^{-3} y^{-\frac{1}{2}}}\right)^{-1}$ jika diketahui nilai $x=8$ dan
$y=\frac{1}{16} !$

Gambar 1. Soal Tes Number Sense

\section{HASIL DAN PEMBAHASAN}

Dalam penelitian ini, subjek penelitian terdiri atas satu siswa bergaya kognitif reflektif (SR) dan satu siswa bergaya kognitif impulsif (SI). Berikut merupakan hasil analisis dan pembahasan dari Tes Number Sense dan wawancara siswa bergaya kognitif reflektif dan impulsif pada materi eksponen. 
Tabel 2. Data hasil TGK dan TKM subjek penelitian

\begin{tabular}{|c|c|c|c|c|}
\hline \multirow{2}{*}{$\begin{array}{c}\text { Kode } \\
\text { subjek }\end{array}$} & \multirow{2}{*}{$\begin{array}{c}\text { Gaya } \\
\text { kognitif }\end{array}$} & \multicolumn{2}{|c|}{ Rata-rata } & \multirow{2}{*}{} \\
\cline { 3 - 4 } & Waktu (detik) & Frekuensi & Skor TKM \\
\hline SR & Reflektif & 94,61 & 1,76 & 100 \\
\hline SI & Impulsif & 43,73 & 3,30 & 100 \\
\hline
\end{tabular}

\section{a. Number sense siswa bergaya kognitif reflektif (SR) pada materi eksponen}

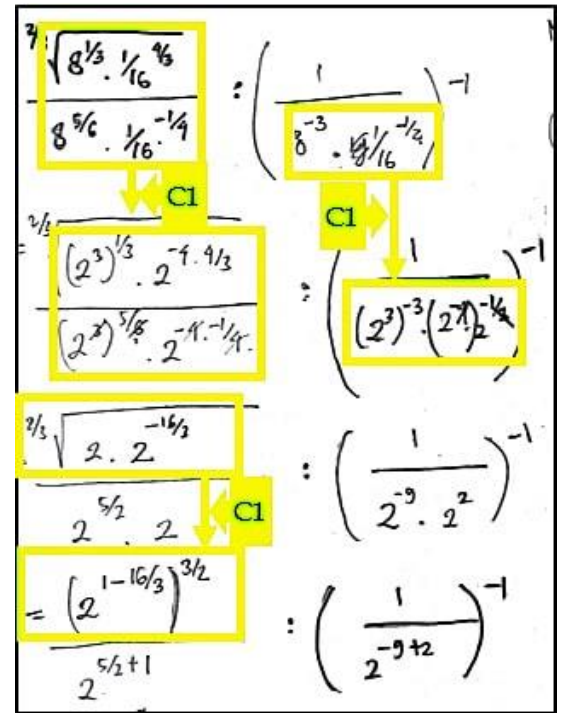

Gambar 2. Hasil TNS SR untuk kode indikator C1

Berdasarkan Gambar 2 dapat dilihat bahwa SR mampu menggunakan konsep bilangan berpangkat dalam penyelesaian TNS yaitu dengan menyederhanakan bilangan-bilangan dari nilai variabel yang diketahui pada soal menjadi bilangan berpangkat dengan basis yang sama untuk memudahkan perhitungan. Selain itu, untuk memperjelas pemahaman SR mengenai eksponen maka dilakukan wawancara sebagai berikut.

P01 : apa yang kamu ketahui mengenai bilangan 7 pangkat $\mathrm{n}$ ?

SR01 : 7 pangkat $\mathrm{n}$ itu seperti 7 pangkat 2, yang berarti 7 kali 7 sebanyak 2 kali.

P02 : lalu bagaimana bila 7 pangkat $n$ ?

SR02 : berarti 7 kali n.

P03 : apakah kamu yakin?

SR03 : iya kak (jeda beberapa menit). Oh ya maaf kak, maksud saya 7 kali 7 sebanyak n kali.

Berdasarkan hasil kutipan wawancara tersebut, menunjukkan bahwa SR menjelaskan makna dari perpangkatan suatu bilangan dengan memberikan contoh terlebih dahulu. SR juga membutuhkan waktu untuk memikirkan jawaban dari pertanyaan wawancara. Hal ini mendukung pernyataan Hassan (2016), bahwa siswa dengan gaya kognitif reflektif cenderung menunda untuk menjawab pertanyaan selama mungkin demi keakuratan jawaban.

Pada Gambar 2 juga menunjukkan bahwa SR mampu memahami makna bilangan dengan bentuk akar dan mampu mengubah bentuk akar menjadi eksponen. Untuk mengetahui alasan SR dalam mengubah bentuk tersebut maka dilakukan wawancara sebagai berikut.

P04 : dimana bentuk akarnya? Apakah kamu mengubahnya?

SR04 : ya, saya mengubahnya karena memang begitu caranya, biasanya saya juga begitu kalau mengerjakan soal yang sejenis dengan soal tersebut.

P05 : apakah kamu mengalami kesulitan saat mengubah bentuk akar menjadi bentuk eksponen?

SR05 : saya sempat lupa rumus, tapi pada akhirnya ingat.

P06 : menurut kamu lebih susah mana antara bentuk pangkat bilangan pecahan dengan pangkat bilangan bulat?

SR06

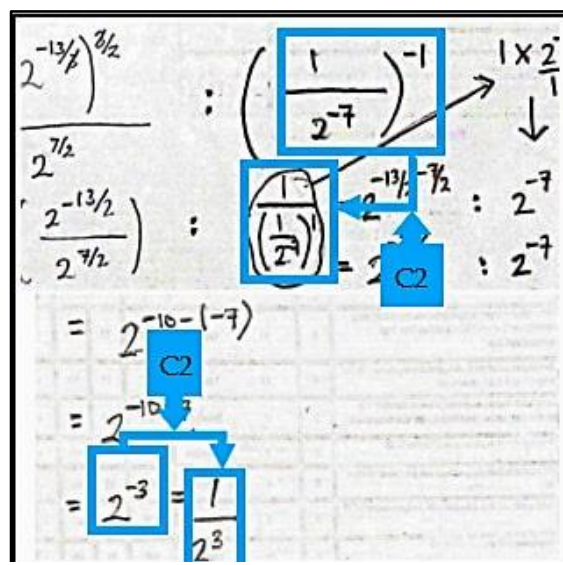

Gambar 3. Hasil TNS SR untuk kode indikator C2

Berdasarkan Gambar 3, menunjukkan bahwa SR mengubah perpangkatan eksponen dengan pangkat bilangan bulat negatif menjadi perpangkatan eksponen dengan pangkat bilangan bulat positif berbentuk pecahan. Kemudian SR mengubah bilangan pecahan berpangkat bilangan bulat negatif dengan pembilang berbentuk eksponen berpangkat bilangan bulat negatif menjadi bilangan pecahan berpangkat bilangan bulat positif dan mengandung eksponen berpangkat bilangan bulat positif. SR mengaku bahwa cara tersebut SR lakukan agar tidak membingungkannya. Hal ini menunjukkan bahwa SR memahami makna eksponen dengan pangkat negatif. SR mampu mengubah bentuk 
eksponen dengan pangkat negatif menjadi bentuk lain yang ekuivalen.

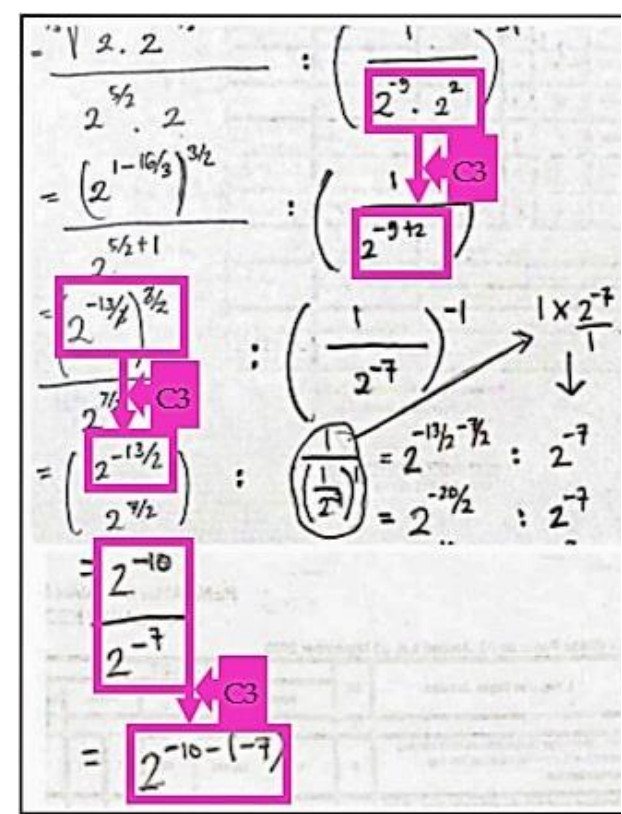

Gambar 4. Hasil TNS SR untuk kode indikator C3

Berdasarkan Gambar 4, menunjukkan bahwa SR mampu menggunakan sifat operasi perkalian eksponen. SR memahami bahwa perkalian eksponen dengan basis yang sama adalah dengan menjumlahkan pangkatpangkatnya. Kemudian, SR menggunakan sifat operasi pembagian eksponen dengan benar. SR juga menggunakan sifat operasi perpangkatan pada eksponen. SR memilih untuk mencoret nilai penyebut dan pembilang dengan nilai yang sama dalam mengalikan kedua pangkat. Hal ini SR lakukan untuk menghemat waktu, sebab SR tidak perlu menghitung kembali. Perilaku SR ini sesuai dengan yang dikemukakan oleh Hassan (2016), bahwa siswa dengan gaya kognitif reflektif bersifat bijaksana yaitu memikirkan sesuatu dari berbagai sudut pandang sebelum bergerak.

Untuk mengetahui strategi perhitungan yang digunakan SR maka dilakukan wawancara sebagai berikut.

P07 : apakah kamu menggunakan kalkulator atau kertas untuk menghitung?

SR07 : saya tidak menggunakan kalkulator tapi menggunakan kertas.

P08 : apakah kamu juga melakukan perhitungan secara mental, maksud saya menghitung hanya dengan membayangkannya saja?

SR08 : iya kak saya juga menghitung dengan membayangkan saja, tapi kalau saya ragu saya akan cek menggunakan hitungan di atas kertas.

Berdasarkan kutipan wawancara di atas, menunjukkan bahwa SR melakukan perhitungan lebih dari sekali untuk memastikan kebenaran hasil perhitungannya. Hal ini sesuai dengan pendapat Hassan (2016), bahwa siswa dengan gaya kognitif reflektif mengamati sesuatu dari berbagai perspektif. Dalam hal ini, SR menghitung dengan dua metode yang berbeda yaitu perhitungan mental dan perhitungan di atas kertas demi keakuratan jawaban.

Dalam penyelesaian TNS, SR memiliki alternatif penyelesaian lain seperti yang tertera pada kutipan wawancara berikut.

P09 : kalau misal diminta untuk menyelesaikan soal itu (TNS) dengan cara yang lain, bagaimana caranya?

SR09 : tidak bisa kak.

P10 : coba kamu pikirkan dahulu, saya beri waktu.

SR10 : saya bisa menghilangkan pangkat -1 dengan cara memecah pangkat -1 sehingga bagian pembilang dan penyebut pecahan tersebut masingmasing pangkatnya -1 .

P11 : lalu mengapa kamu tidak mengerjakan dengan cara seperti itu?

SR11 : karena kalau seperti itu, butuh waktu lebih lama kak.

Berdasarkan hasil kutipan wawancara di atas, menunjukkan bahwa SR pada mulanya mengaku tidak bisa menyelesaikan TNS dengan cara lain. Akan tetapi setelah diberi waktu untuk berpikir, SR mampu menjelaskan cara lain yang akan SR gunakan untuk menyelesaikan TNS. Dengan kata lain, siswa dengan gaya reflektif membutuhkan waktu lebih banyak untuk berpikir (Nietfield \& Bosma, 2003). SR mampu menyelesaikan TNS dengan cara lain, mengindikasikan bahwa SR memahami dengan baik sifat-sifat eksponen dan SR mampu memilih cara paling efektif yang harus SR gunakan.

SR juga mampu memilih cara yang efektif untuk mensubstitusikan nilai variabel yaitu mensubstitusikan nilai variabel yang diketahui pada soal di awal pengerjaan karena SR merasa lebih mudah dibanding dengan menyelesaikan soal dengan bentuk variabel. Untuk mengetahui keyakinan SR pada jawabannya dan apakah SR mengecek kembali jawabannya sebelum dikumpulkan maka dilakukan wawancara.

P12 : apabila diberi waktu tambahan untuk mengerjakan kembali, bagian mana yang ingin kamu perbaiki? 
SR12 : saya yakin dengan jawaban saya kak dan tidak ingin memperbaikinya.

P13 : apakah sebelum mengirim jawaban, kamu mengecek kembali jawaban kamu?

SR13 : ya, saya sudah koreksi jawaban saya.

Dari kutipan wawancara di atas, SR mampu menilai kewajaran komputasi jawaban yang telah SR tulis dengan cara mengoreksi lembar jawaban sebelum dikumpulkan dan merasa yakin pada jawabannya. Selain itu, sesuai dengan pendapat Nietfield dan Bosma (2003) serta menurut Shafiee \& Khavaran (2017) bahwa siswa dengan gaya kognitif reflektif berhati-hati dalam bertindak dan berpikir relatif kompleks serta cenderung bekerja secara akurat dan cermat. Pemahaman dan kecermatan SR pada materi eksponen menjadikan hasil perhitungan SR dalam pengerjaan TNS juga tepat. Berdasarkan hasil analisis TNS dan wawancara di atas, dapat disimpulkan bahwa SR telah memenuhi semua indikator number sense pada materi eksponen yang disajikan dalam tabel 1.

\section{b. Number sense siswa bergaya kognitif impulsif (SI) pada materi eksponen}

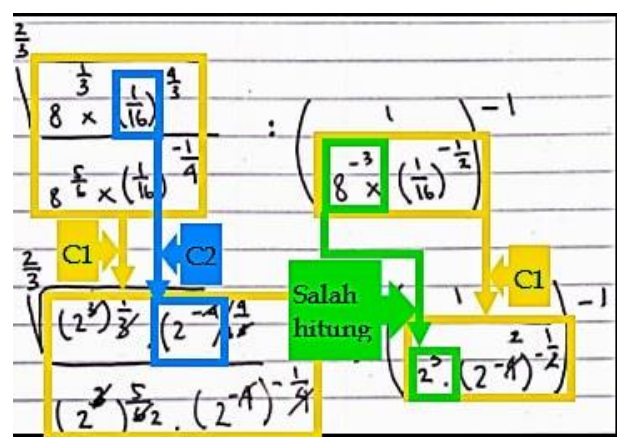

Gambar 5. Hasil TNS SI untuk kode indikator C1 dan $\mathrm{C} 2$

Untuk mengetahui pemahaman SI mengenai eksponen maka dilakukan wawancara sebagai berikut.

P01 : apa yang kamu ketahui mengenai bilangan 7 pangkat $n$ ?

SI01 : 7 kali 7 sebanyak bilangan tersebut (n).

Dari kutipan wawancara di atas, dapat diketahui bahwa SI memahami definisi eksponen dan mampu menerapkannya dalam penyelesaian TNS seperti yang ada pada Gambar 5. Berdasarkan Gambar 5, SI menunjukkan kemampuannya dengan menyederhanakan bilangan yang diketahui pada soal menjadi eksponen dengan basis yang sama untuk memudahkan penyelesaian TNS. Namun SI membuat kesalahan, SI menyederhanakan bilangan 8 dengan mengabaikan bahwa bilangan 8 berpangkat -3 sebab SI tidak memperhatikan pangkat dari bilangan 8. Sejalan dengan Matczak (1992) dalam Michalska \& Lamparska
(2015), bahwa siswa dengan gaya kognitif impulsif cenderung menggunakan jawaban pertama yang muncul dalam pikiran mereka tanpa memperhatikan kebenarannya. Hal inilah yang menjadi penyebab ketidaktelitian SI.

Pada indikator menggunakan beberapa representasi bilangan dan operasinya, ditunjukkan SI pada Gambar 5 melalui caranya mengubah bilangan pecahan biasa dengan pembilang bernilai 1 menjadi eksponen dengan pangkat negatif yang bernilai ekuivalen. Namun, jawaban TNS SI berhenti pada langkah mengubah bentuk akar menjadi bentuk eksponen. Untuk mengetahui alasan SI, maka dilakukan wawancara sebagai berikut.

P02 : mengapa jawaban kamu tidak selesai?

SI02 : saya sudah tidak bisa kak.

P03 : apakah kamu lupa?

SI03 : saya tidak tahu kak, sudah tidak bisa berpikir.

P04 : padahal tadi waktunya masih tersisa, kamu bisa berusaha kembali.

SI04 : percuma juga kak, saya sudah tidak tahu.

Dari kutipan wawancara di atas, dapat diketahui bahwa SI tidak mampu mengubah bentuk akar menjadi bentuk lain yang ekuivalen. SI mengaku sudah tidak tahu apa yang harus SI lakukan, SI juga terkesan menyerah pada keadaan. Hal ini sejalan dengan hasil penelitian Rahmatina dkk. (2014) bahwa siswa bergaya kognitif impulsif memiliki tingkat rasa ingin tahu yang biasa saja, soal yang sulit tidak menjadi tantangan bagi mereka dan mereka lebih memilih untuk meninggalkannya.

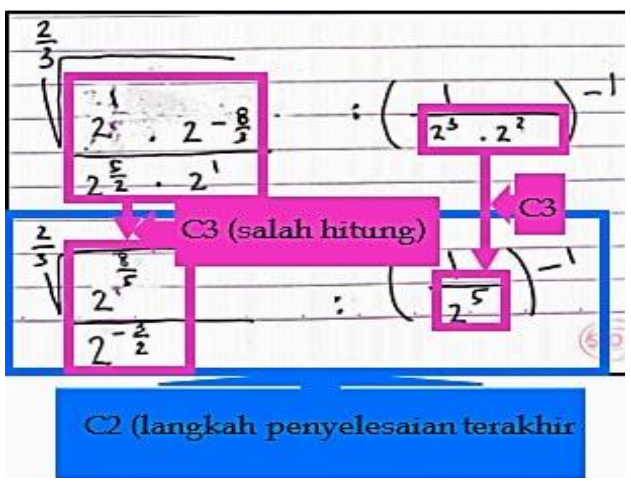

Gambar 6. Hasil TNS SI untuk kode indikator C2 dan C3

Gambar 6 merupakan langkah penyelesaian TNS terakhir yang diselesaikan oleh SI. Penyelesaian TNS oleh SI terhenti karena tidak dapat mengubah bentuk akar. Sehingga dilakukan wawancara untuk mengetahui kemampuan SI dalam mengoperasikan perpangkatan eksponen dengan pangkat negatif sebagai berikut. 
P05 : menurut kamu dalam bentuk ini $\left(\frac{1}{2^{5}}\right)^{-1}$, bagaimana caranya agar pangkat -1 hilang?

SI05 : $2^{5}$ pindah ke atas jadi $2^{-5}$ lalu $\left(2^{-5}\right)^{-1}$ sehingga jadi positif.

Dari kutipan wawancara tersebut, SI sebenarnya mampu melanjutkan akan tetapi terhalang oleh ketidakmampuannya untuk mengubah bentuk akar menjadi bentuk eksponen.

Berdasarkan Gambar 6, SI telah memenuhi indikator memahami efek dari operasi bilangan. SI menggunakan sifat operasi perkalian pada eksponen, terdapat tiga operasi perkalian yang SI lakukan akan tetapi dua di antaranya tidak benar. Hasil operasi perkalian yang benar adalah operasi perkalian eksponen dengan pangkat bilangan bulat. Sedangkan hasil operasi perkalian yang salah adalah operasi eksponen dengan pangkat bilangan pecahan. Kesalahan yang dilakukan SI disebabkan oleh ketidaktelitiannya dalam menggunakan rumus perkalian eksponen. Kemudian, untuk mengetahui alasan SI dalam menggunakan sifat operasi perkalian yang kurang tepat maka dilakukan wawancara sebagai berikut.

P06 : apakah itu memang $2^{\frac{8}{5}}$ ? Dapat dari mana?

SI06 : iya $2^{\frac{8}{5}}$, pangkatnya itu dapat dari $1-\frac{8}{3}$ kemudian menjadi $\frac{8}{8}-\frac{8}{3}$.

P07 : apakah kamu yakin begitu?

SI07 : yakin kak, yang atas (pembilang) tetap dan bawahnya (penyebut) yang dikurangi.

P08 : lalu $2^{\frac{-3}{2}}$ dapat dari mana?

SI08 : dapat dari $\frac{5}{2}+1$ kemudian menjadi $\frac{5}{2}+$ $\frac{2}{2}$, yang atas ditambah dan yang bawah tetap.

P09 : berarti seharusnya $\frac{7}{2}$ ?

SI09 : oh iya benar, maaf kak saya tidak teliti

Berdasarkan kutipan wawancara di atas, SI tidak konsisten pada caranya dalam menggunakan sifat operasi perkalian eksponen. Dan penggunaan sifat perkalian eksponen yang SI terapkan juga tidak tepat. SI kurang memahami konsep penjumlahan pecahan dengan penyebut berbeda. Namun, SI menyadari bahwa SI tidak teliti dalam melakukan perhitungan. Sesuai pernyataan Hassan (2016), bahwa siswa dengan gaya kognitif impulsif bertindak secara spontan tanpa memikirkannya konsekuensinya. Hal tersebut mengakibatkan SI tidak teliti dalam menyelesaikan TNS.

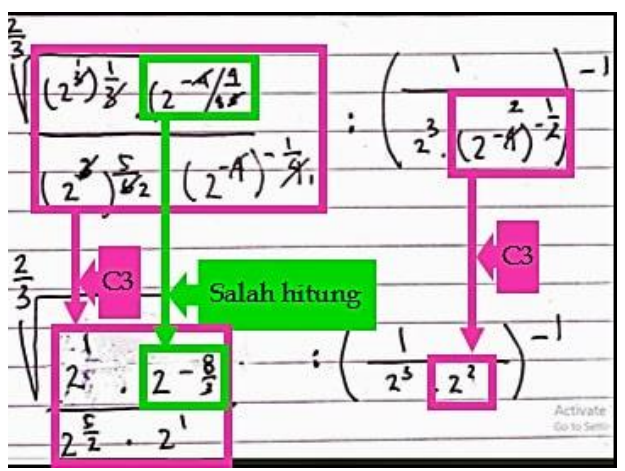

Gambar 7. Hasil TNS SI untuk kode indikator C3

Berdasarkan Gambar 7, SI mampu menggunakan operasi perpangkatan eksponen. Namun, terdapat operasi perpangkatan yang kurang tepat. SI tidak teliti dalam mengalikan -4 dengan 4 , yang seharusnya -16 menjadi -8 .

Pada indikator mampu menilai kewajaran komputasi dari strategi berbeda, dilakukan wawancara untuk mengetahui strategi perhitungan yang digunakan SI dan cara penyelesaian lain yang dapat digunakan SI sebagai berikut.

P10 : apakah kamu menggunakan kalkulator atau kertas untuk menghitung?

SI10 : tidak kak, saya mencoret-coret di kertas.

P11 : apakah kamu juga melakukan perhitungan secara mental, maksud saya menghitung hanya dengan membayangkannya saja?

SI11 : iya kak.

P12 : kalau diminta mengerjakan ulang dengan cara yang berbeda, bagaimana cara kamu? Coba jelaskan!

SI12 : tidak tahu kak, saya sudah tidak bisa berpikir.

Berdasarkan kutipan wawancara di atas, SI menggunakan strategi perhitungan di atas kertas dan perhitungan mental. Kemudian, SI juga tidak memiliki gambaran untuk menyelesaikan TNS dengan cara lain. Hal ini sesuai dengan pendapat Rahmatina dkk. (2014), bahwa siswa dengan gaya kognitif impulsif menggunakan cara-cara secara singkat dan cepat untuk menyelesaikan sesuatu, juga cara yang biasa mereka temukan dalam soal sehingga mereka tidak dapat memberikan alternatif lain. SI dapat memilih cara yang efektif dalam mensubstitusikan nilai variabel yang diketahui pada soal yaitu di awal pengerjaan karena SI merasa lebih mudah dibanding dengan menyelesaikan soal dengan bentuk variabel. 
SI merasa yakin pada jawaban TNS yang telah ia selesaikan, namun ia cenderung merasa putus asa untuk melanjutkan penyelesaian TNS. Hal ini diketahui berdasarkan hasil wawancara berikut.

P13 : apakah kamu yakin dengan jawabanmu?

SI13 : yakin kak, tapi belum selesai. Saya merasa susah untuk mengubah bentuk akarnya.

P14 : apa kamu mengecek kembali jawabanmu sebelum dikumpulkan?

SI14 : tidak kak, langsung saya kumpulkan. Percuma juga kak, tetap saja tidak bisa melanjutkan.

Dari kutipan wawancara di atas, menunjukkan bahwa SI yakin dengan jawabannya padahal SI tidak mengecek kembali jawabannya. SI mengumpulkan jawaban sebelum durasi waktu yang diberikan habis. Saat peneliti mengingatkan bahwa waktu masih tersisa, SI tetap tidak ingin melanjutkan. Oleh karena itu, SI tidak memenuhi indikator menilai kewajaran komputasi. SI tidak berhasil menyelesaikan TNS hingga menemukan hasil akhir, akan tetapi berhenti di tengah jalan karena SI tidak memahami konsep bentuk akar. Sejalan dengan karakteristik siswa impulsif menurut Nietfield \& Bosma (2003), bahwa siswa dengan gaya kognitif impulsif bertindak spontan dan membuat banyak kesalahan. Rahmatina dkk. (2014) menyebutkan salah satu karakteristik siswa bergaya kognitif impulsif adalah kurang konsentrasi dalam kelas. Oleh sebab itu SI melakukan banyak kesalahan, baik karena kurangnya pemahaman konsep eksponen maupun karena tidak teliti. Berdasarkan hasil analisis TNS dan wawancara di atas, SI tidak dapat memenuhi indikator mampu menilai kewajaran komputasi. Hal ini karena SI tidak mampu menjelaskan alternatif lain penyelesaian TNS dan tidak melakukan pengecekan kembali jawaban TNS sebelum dikumpulkan.

\section{c. Perbedaan Number Sense Siswa Dengan Gaya} Kognitif Reflektif dan Impulsif

Berdasarkan hasil dan pembahasan penelitian di atas, dapat disajikan perbedaan number sense siswa bergaya kognitif reflektif dan impulsif pada materi eksponen sebagai berikut.

Tabel 3. Hasil analisis number sense

\begin{tabular}{|l|l|l|}
\hline \multicolumn{1}{|c|}{ Indikator } & \multicolumn{1}{|c|}{ Siswa Reflektif } & \multicolumn{1}{c|}{ Siswa Impulsif } \\
\hline Siswa dapat & Dapat menjelaskan & Dapat \\
menggunakan & dan menerapkan & menjelaskan dan \\
konsep bilangan & definisi eksponen, & menerapkan \\
berpangkat & mengubah bentuk akar & definisi eksponen, \\
yaitu perkalian & menjadi eksponen, dan & tidak dapat \\
berulang atau & dapat menyelesaikan & mengubah bentuk \\
konsep bentuk & TNS dengan baik & akar menjadi \\
akar & & eksponen, dan \\
& & tidak dapat \\
\hline
\end{tabular}

\begin{tabular}{|l|l|l|}
\hline & & menyelesaikan \\
TNS dengan baik
\end{tabular}

\section{PENUTUP}

\section{Simpulan}

Berdasarkan hasil penelitian dapat disimpulkan bahwa number sense siswa bergaya kognitif reflektif dan impulsif 
pada materi eksponen berbeda. Pada indikator siswa dapat menggunakan konsep bilangan berpangkat yaitu perkalian berulang atau konsep bentuk akar, kedua siswa mampu menjelaskan definisi eksponen. Namun, siswa impulsif tidak memahami hubungan antara bentuk akar dengan eksponen dan tidak dapat menyelesaikan TNS hingga menemukan hasil akhir. Pada indikator siswa dapat mengubah suatu ekspresi eksponen menjadi bentuk ekspresi lain yang ekuivalen dan sebaliknya sesuai dengan sifat-sifat eksponen, kedua siswa dapat mengubah bentuk eksponen berpangkat positif menjadi negatif dengan nilai yang ekuivalen. Pada indikator siswa dapat memanfaatkan sifat-sifat operasi eksponen untuk menentukan hasil operasi eksponen, siswa reflektif dapat menggunakan sifat operasi perkalian, pembagian, dan perpangkatan eksponen dengan baik. Sedangkan siswa impulsif dapat menggunakan sifat operasi perkalian dan perpangkatan serta membuat beberapa kesalahan karena kurangnya pemahaman akan konsep eksponen. Pada indikator siswa dapat menggunakan strategi (perhitungan mental, perhitungan di atas kertas) yang efektif, kedua siswa menggunakan perhitungan mental dan perhitungan kertas. Namun, siswa reflektif menggunakan perhitungan kertas untuk mengecek kembali hasil perhitungan mental. Pada indikator siswa dapat menggunakan strategi yang berbeda dalam penyelesaian soal, siswa reflektif dapat menjelaskan alternatif lain untuk penyelesaian TNS akan tetapi tidak dengan siswa impulsif. Pada indikator siswa dapat menilai kewajaran hasil komputasi dengan mengecek kembali jawaban yang didapatkan, siswa reflektif mengecek kembali jawabannya sebelum dikumpulkan. Sedangkan siswa impulsif tidak mengecek kembali dan mengalami beberapa ketidaktelitian.

\section{Saran}

Hasil penelitian menunjukkan bahwa hasil Tes Number Sense siswa bergaya kognitif reflektif lebih baik dibanding siswa bergaya kognitif impulsif. Hal ini dikarenakan kurangnya pemahaman materi pada siswa bergaya kognitif impulsif dan kurang teliti. Untuk itu disarankan bagi guru agar memotivasi siswa terutama yang bergaya kognitif impulsif agar lebih teliti dalam menyelesaikan suatu soal.

Dalam penelitian ini pemberian instrumen Tes Gaya Kognitif (Matching Familiar Figure Test) dilakukan secara online sehingga terkendala oleh sinyal jaringan. Untuk itu dalam penelitian number sense selanjutnya, disarankan agar menentukan cara lain yang tepat untuk digunakan dalam pemberian Tes Gaya Kognitif (Matching Familiar Figure Test).

\section{DAFTAR PUSTAKA}

Arslan, O. (2016). An Investigation of Students' Number Sense and Attitude Scores As Predictors of Mathematics Achievment. Ankara: Ihsan Dogramaci Bilkent University.

Castronovo, J., \& Gobel, S. M. (2012). Impact of HIgh Mathematics Education on the Number Sense. PLoS ONE, 7(4), 1-16. doi:10.1371/journal.pone.0033832

Cheung, K. L., \& Yang, D. C. (2018). Examining the Different of Hong Kong and Taiwan Student' Performance on the Number Sense Three-tier Test. EURASIA Journal of Mathematics, Science and Technology Education, 14(7), 3329-3345. doi:10.29333/ejmste/91682

Chrysostomou, M., Tsingi, C., Cleanthous, E., \& Pantazi, D. P. (2011). Cognitive Style and Their Relation to Number Sense and Algebraic Reasoning. Proceeding of the Seventh Conference of the European Research in Mathematics Education.

Clarke, M. C., \& Wessels, H. M. (2014). Number Sense of Final Year PreService Primary School Teachers. Journal in Phytagoras.

Hassan, A. (2016). Influence of Reflective and Impulsive Cognitive Style on Academic Self-Efficacy among Senior Secondary Student in Kaduna State. Nigeria: Ahmadu Bello University.

Iymen, E., \& Paksu, A. D. (2015). Analysis of 8th Grade Students' Number Sense Related to the Exponents in Terms of Number Sense Components. Education and Science, 40(177), 109-125. doi:10.15390/eb.2015.2710

Maghfirah, M., \& Mahmudi, A. (2018). Number Sense: the Result of Mathematical Experience. Journal of Physic: Conference Series. doi:10.1088/17426596/1097/1/012141

Michalska, P., \& Lamparska, L. Z. (2015). The Measurement of Cognitive Style ReflectionImpulsivity in the Adul-Hood Result of Own Study. Polskie Forum Psychologiczne, 20(4). doi:10.14656/PFP20150408

Mohamed, M., \& Johnny, J. (2010). Investigating Number Sense Among Students. International Conference on Mathematics Education Research 2010 (ICMER 2010) (hal. 317-324). Procedia Social and Behavioral Sciences. doi:10.1016/j.sbspro.2010.12.044

Nietfield, J., \& Bosma, A. (2003). Examining the SelfRegulation of Impulsive and Reflective Response Style on Academic Tasks. Journal of Research in Personality, 37(3), 118-140. doi:10.1016/S00926566(02)00564-0

Olagbaju, O. O. (2020). Cognitive Styles and Gender as Predictors of Students' Achievement in Summary 
Writing in Selected Secondary Schools in Ibadan, Nigeria. Education Research International 2020, 19. doi:10.1155/2020/8462368

Rahmatina, S., Sumarmo, U., \& Johar, R. (2014). Tingkat Berpikir Kreatif Siswa dalam Menyelesaikan Masalah Matematika Berdasarkan Gaya Kognitif Reflektif dan Impulsif. Jurnal Didaktik Matematika, 1(1).

Shafiee, S., \& Khavaran, S. R. (2017). Effects of Cooperative Learning on Vocabulary Achievement of Reflective / Impulsive Irania EFL Learners. International Journal of Foreign Language Teaching \& Research, 5(11).

Sugiyono. (2017). Metode Penelitian Pendidikan: Pendekatan Kuantitatif, Kualitatif, dan R\&D. Bandung: Alfabeta.

Sumaryanta, S., Priatna, N., \& Sugiman. (2019). Pemetaan Hasil Ujian Nasional Matematika. IDEAL MATHEDU: Indonesian Digital Journal of Mathematics and Education, 6(1), 543-557.

Tosto, M. G., Ptrill, S. A., Malikh, S., Malki, K., Haworth, C. M., Mazzocco, M. M., . . . Kovas, Y. (2017).
Number Sense and Mathematics: Which, When, and How? Developmental Psychology.

Ulusoy, F. (2019). Serious Obtacles Hindering Middle School Students' Understanding of Integer Exponents. International Journal of Research in Education and Science (IJRES), 52-69.

Warli. (2010). Instrumen Matching Familiar Figure Test (MFFT). Dipetik Desember 01, 2020, dari http://ecampus.fkip.unja.ac.id/repository/file?i=hKuDbsUvFh099HM8W9rcJga-XtAfu8kJ8wEs15coso

Yang, D. C., \& Wu, W. R. (2010). The Study of Number Sense: Realistic Activities Integrated into ThirdGrade Math Classes in Taiwan. Journal of Educational Research, 103(6), 379-392. doi:10.1080/00220670903383010

Zainal. (2018). 7th Grade Students' Number Sense Based on Reflective and Impulsive Cognitive Style. Mathematics, Informatics, Science, and Education International Conference (MISEIC 2018). 157, hal. 210-212. Advances in Intelligent Systems (AISR) 